RESEARCH NOTES

\title{
ON THE COEFFICIENT DOMAINS OF UNIVALENT FUNCTIONS
}

\author{
M.M. ELHOSH \\ Department of Mathematics \\ The University College of Wales \\ Aberystwyth, Wales \\ United Kingdom \\ (Recelved March 10, 1987)
}

ABSTRACT. Coefficient domains for functions whose derivative has positive real part in the interior of an ellipse are given in this paper.

KEY WORDS AND PHRASES. Univalent functions.

1980 AMS CLASSIFICATION CODES. Primary 30C45, $30 \mathrm{C} 50$.

1. INTRODUCTION.

Let $f(z)$ be regular and satisfy the condition

$\operatorname{Re} f^{\prime}(z)>0$

in a domain D. Then it is wellknown (see [1, p. 582], [2]) that $f(z)$ is univalent in

D. Let $D$ be the interior of a fixed ellipse

$E_{0}=\left\{z=\cosh \left(s_{0}+1 \tau\right), 0<\tau<2 \pi, s_{0}=\tanh ^{-1}(b / a), a>b>0\right\}$ with foc1 \pm 1 . Let $r_{0}=a+b$ be the sum of the semi-axes of the ellipse $E_{0}$ and set $z=\cosh n$ where

$n=s+i \tau$ and $0<s<s_{0}$. Then we see from the operator $\partial / \partial z=\partial / \partial \eta$ that $(1.1)$ become 8

$$
\operatorname{Re} \sqrt{2-1} f^{\prime}(z)>0
$$

for $z$ in $\operatorname{Int}\left(\mathrm{E}_{\mathrm{o}}\right)$

In this note we shall study coefficient domains for functions which are regular and satisfy $(1.2)$ in $\operatorname{Int}\left(E_{0}\right)$. In connection with this problem see [3, Problem 6.54], [4, Problem 7.2], [5], [6], and [7] and [8, p.141]. 
THEOREM. Let $f(z)=\sum_{n=1}^{\infty} a_{n} T_{n}(z)$ be regular and satisfy (1.2) in Int( $\left.E_{0}\right)$. Then for $n>1$ we have the sharp inequalities

$$
\begin{aligned}
& \left|a_{n}\right|<2 / n \sinh n s_{0}, \\
& \alpha_{n}^{2} \sinh ^{2} n s_{0}+\beta_{n}^{2} \cosh ^{2} n s_{0}<4 / n^{2} .
\end{aligned}
$$

The inequality (1.4) shows that the coefficients $a_{n}$ lie in ellipses with centre at the origin and semi-axes $4 / n\left(r_{0}^{n} \pm r_{0}^{-n}\right)$ where $n=1,2,3, \ldots$.

PROOF OF THE THEOREM. We see from $(1.2)$, setting $z=\cosh \left(s_{0}+1 \tau\right), s_{0}=\log r_{0}$ and $a_{n}=\alpha_{n}+i \beta_{n}$, that

$$
\operatorname{Re}\left[1+\sqrt{z^{2}}-1 f^{\prime}(z)\right]=1+\sum_{n=1}^{\infty} n\left(\alpha_{n} \sinh n s_{0} \cos n \tau-\beta_{n} \cosh n s_{0} \sin n \tau\right)
$$

where $\operatorname{Re}\left[1+\sqrt{z^{2}}-1 f^{\prime}(z)\right]>0$ in $\operatorname{Int}\left(E_{0}\right)$.

Since this is a Fourier series for fixed ${ }_{0}$; we then see that

$$
\begin{aligned}
& \int_{0}^{2 \pi} \operatorname{Re}\left[1+\sqrt{z^{2}-1} f^{\prime}(z)\right] d \tau=2 \pi, \\
& \int_{0}^{2 \pi} \operatorname{Re}\left[1+\sqrt{z^{2}-1} f^{\prime}(z)\right] \cos n \tau=n \pi 1 \alpha_{n} \sinh n s_{0}, \\
& \int_{0}^{2 \pi} \operatorname{Re}\left[1+\sqrt{z^{2}-1} f^{\prime}(z)\right] \sin n \tau=n \pi 1 \beta_{n} \cosh n s_{0} .
\end{aligned}
$$

Us ing (1.5), (1.6), and (1.7) we obtain

$$
\begin{aligned}
\left|a_{n}\right| & =\left|\alpha_{n}+i \beta_{n}\right| \\
& =\left|\frac{1}{n \pi 1} \int_{0}^{2 \pi} \frac{\sinh n\left(s_{0}+i \tau\right) \operatorname{Re}\left[1+\sqrt{z^{2}}-1 f^{\prime}(z)\right]}{\sinh n s_{0} \cosh n s_{0}} d \tau\right| \\
& <\frac{1}{n \pi \sinh n s_{0}} \int_{0}^{2 \pi} \operatorname{Re}\left[1+\sqrt{z^{2}-1} f^{\prime}(z)\right] d \tau \\
& <2 / n \sinh n s_{0}
\end{aligned}
$$

since $\left|\sinh n\left(s_{0}+1 \tau\right)\right|<\cosh$ ns. $_{0}$ This is (1.3). 
We also see form $(1.5),(1.6)$ and (1.7) that

$$
\begin{aligned}
\left|\alpha_{n} \sinh n s_{0}+1 \beta_{n} \operatorname{coshns}\right| & =\left|\frac{1}{n \pi i} \int_{0}^{2 \pi} \operatorname{Re}\left[1+\sqrt{z^{2}}-1 f^{\prime}(z)\right] e^{n i \tau} d \tau\right| \\
& <2 / n .
\end{aligned}
$$

This gives

$$
\alpha_{n}^{2} \sinh ^{2} n s_{0}+B_{n}^{2} \cosh ^{2} n s_{0}<4 / n^{2}
$$

as required in (1.4) and the proof of the theorem is complete.

Finally we see from [9, Theorems 2 and 6] that

$$
f^{\prime}(z)=-1 / \sqrt{z^{2}}-1+\int_{0}^{2 \pi}\left(K(z, \bar{\xi}) / \sqrt{z^{2}}-1\right) d \psi\left(\tau^{\prime}\right)
$$

where $\xi=\cosh \left(s_{0}+1 \tau^{\prime}\right), z=\cosh (s+1 \tau), 0<s<s_{0}, 0<\tau^{\prime}<2 \pi$ and

$0<\tau<2 \pi$ plays the role of the extermal function in this case.

REMARK. Normalizing in the sense of [3, Remark 2] we obtain the analogous results in [2, Theorem 1].

\section{REFERENCES}

1. KAPLAN, W. Advanced Calculus, Addison-Wesley (1952).

2. MacGREGOR, T.H. Functions whose derivative has a positive real part. Trans. Amer. Math. Soc. 104 (1962), 532-537.

3. ANDERSON, J.M., BARTH, K. F. and BRANNAN, D.A. Research problems in complex analysis, Bull. London Math. Soc. 9 (1977), 129-162.

4. HAYMAN, W.K. Research problems in function theory, Athlone Press, London (1967).

5. ROYSTER, W.C. Functions having positive real part in an ellipse, Proc. Amer. Math. Soc. 10 (1959), 266-269.

6. ROYSTER, W.C. Coefficient problems for functions regular in an ellipse, Duke Math. J. 26 (1959), 361-372.

7. SCHAEFFER, A.C. and SPENCER, D.C. Coefficient regions for Schlicht functions, Ame r. Math. Soc., Collog. Pub. 35 (1950).

8. SHAFFER, D.B. The Biekerbach conjecture, Contemporary Math. 38 (1985), 139-141.

9. ROYSTER, W.C. A Poisson integral formula for the ellipse and some applications. Proc. Amer. Math. Soc. 15 (1964), 661-670.

10. ELHOSH, M.M. On mean p-valent functions in an ellipse, Proc. Roy. Soc. Edinburgh 92A (1982), 1-11. 


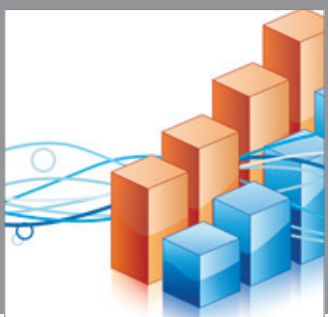

Advances in

Operations Research

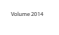

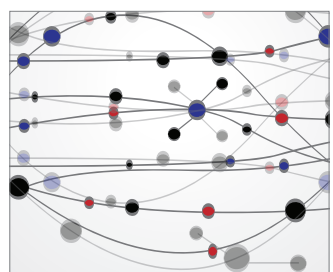

\section{The Scientific} World Journal
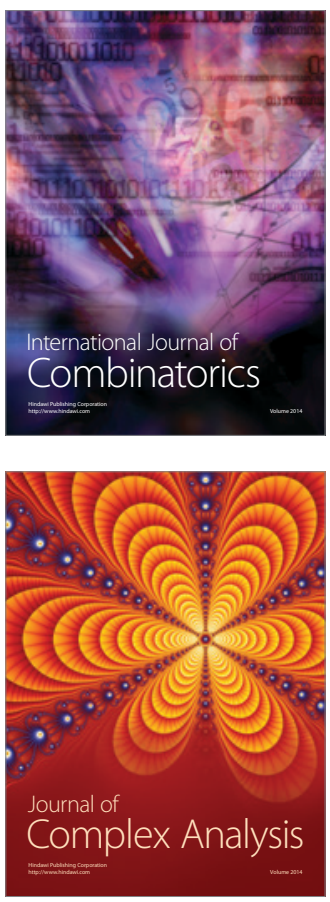

International Journal of

Mathematics and

Mathematical

Sciences
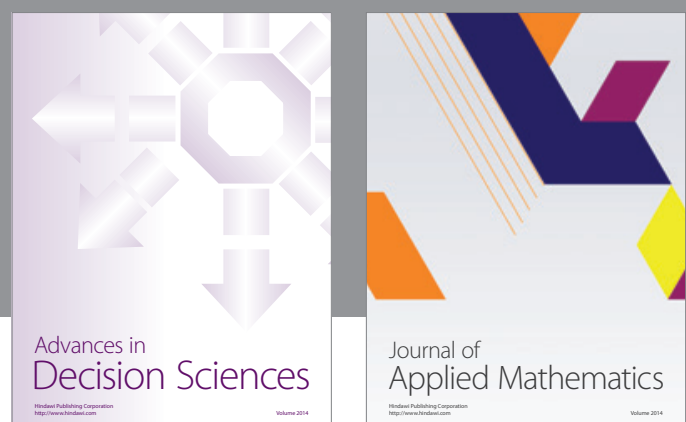

Journal of

Applied Mathematics
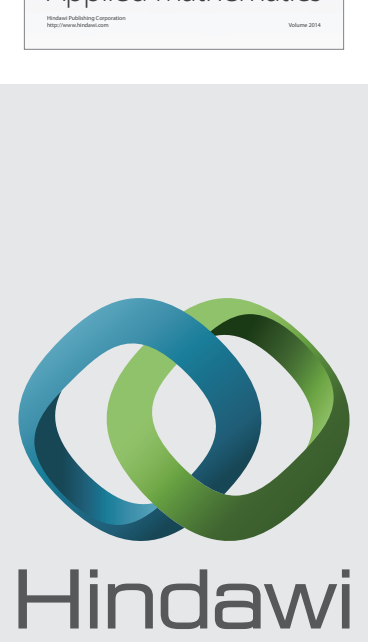

Submit your manuscripts at http://www.hindawi.com
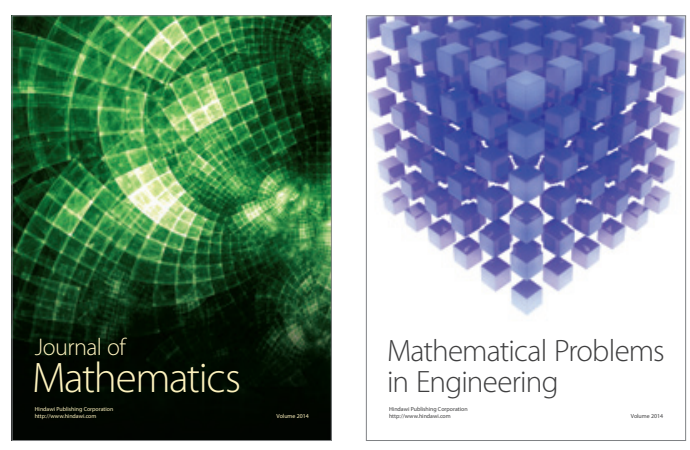

Mathematical Problems in Engineering
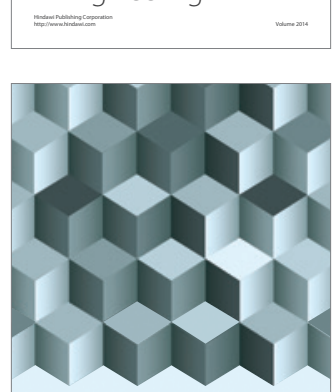

Journal of

Function Spaces
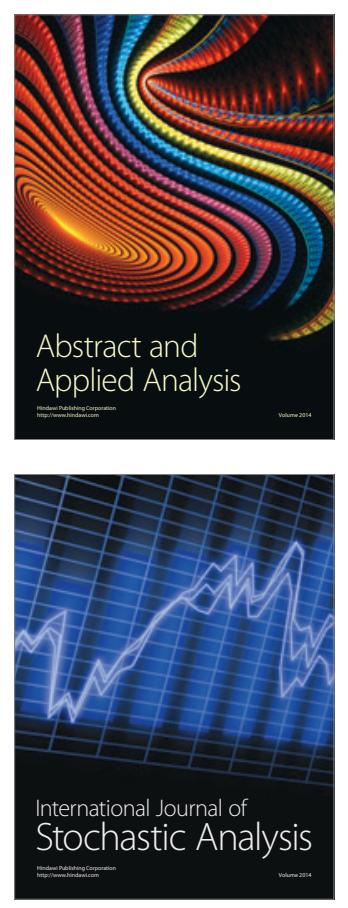

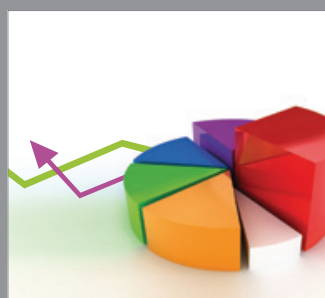

ournal of

Probability and Statistics

Promensencen
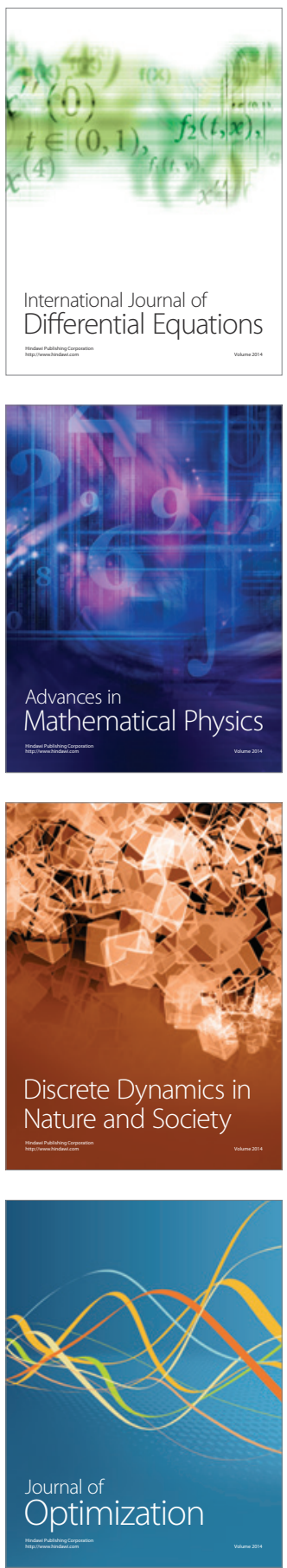